\title{
CONFIGURAÇÃO DOS RELACIONAMENTOS ENTRE PRODUTORES AGROPECUÁRIOS E COOPERATIVAS
}

\section{CONFIGURATION OF RELATIONSHIPS BETWEEN AGRICULTURAL PRODUCERS AND COOPERATIVES}

\author{
Juliano Nunes Alves \\ admjuliano@yahoo.com.br \\ Universidade de Cruz Alta - Cruz Alta - RS \\ Tiago Zamberlan \\ tiagozamberlan@yahoo.com.br \\ Universidade de Cruz Alta - Cruz Alta - RS \\ Denise Rossato Quatrin \\ dequatrin@gmail.com \\ Universidade de Cruz Alta - Cruz Alta - RS
}

\section{Resumo}

Dada a importância crescente das mais diversas formas de cooperação, esse estudo visa avaliar como se configuram os relacionamentos entre produtores agropecuários e cooperativas, identificando as motivações para tal e a presença das óticas social e humana e econômica. Para tal, foram entrevistados produtores agropecuários associados a cooperativas e, como principais resultados, destaca-se que os cooperados buscam primeiramente vantagens diretamente ligadas à atividade econômica que desenvolvem, mas que com o passar do tempo questões de aprendizado também passam a ser importantes para a continuidade do relacionamento. Ainda, as cooperativas precisam investir na transparência de suas decisões, ações e distribuição de recursos, importante fator para fidelização de seus cooperados.

Palavras-chave: Cooperativa. Produtores agropecuários. Plano de ação.

\begin{abstract}
Given the increasing importance of the diverse forms of cooperation, this study aims to evaluate how are configured the relationships between agricultural producers and cooperatives, identifying the motivations for this and the presence of human and social perspective, as well as economic. For this, it was interviewed some partners of cooperatives and as main results we emphasize that the partners first seek benefits directly linked to economic activity that they develop, but along the time, learning issues also become important for the continuity of the relationship. Moreover, cooperatives need to invest in the transparency of its decisions, actions and distribution of resources, an important factor for retention of their members.
\end{abstract}

Keywords: Cooperative. Agricultural producers. Action plan. 


\section{CONFIGURAÇÃO dOS RELACIONAMENTOS ENTRE PRODUTORES AGROPECUÁRIOS E COOPERATIVAS}

\section{Introdução}

Atualmente o cooperativismo apresenta-se como uma alternativa para pequenos, médios e grandes produtores, os quais vêm evoluindo na forma de organização e na produção de um trabalho diferenciado, dando indícios de que os objetivos de maior eficiência e eficácia na produção agrícola podem ser alcançados com um bom relacionamento. No contexto competitivo onde os produtores agropecuários estão inseridos, intensificado pela dramática abertura econômica do Brasil (COUTINHO e FERRAZ, 1993), a participação em cooperativas possibilita rever algumas estratégias, bem como as estruturas organizacionais e as formas de cooperar, que são algumas ações utilizadas para aumentar o relacionamento entre o cooperado e suas cooperativas.

Conforme Constantino (2010), os associados têm uma participação ativa no cooperativismo agropecuário e podem, junto com a sua cooperativa, crescer e desenvolver suas atividades. Compreende-se essa afirmação pelo fato de a cooperativa depender de seus associados para obter bons resultados e os associados dependerem da cooperativa para terem vantagens competitivas, havendo um crescimento para ambas as partes. E ainda, Oliveira (2004, p. 36) afirma que "o exercício sistemático do planejamento tende a reduzir a incerteza envolvida no processo decisório e, consequentemente, provocar o aumento da probabilidade de alcance dos objetivos, desafios e metas estabelecidos".

Dado esse contexto, o presente trabalho pretende identificar os relacionamentos entre produtores agropecuários e cooperativas, verificando se os mesmos atendem às demandas e necessidades dos produtores, e o que pode ser feito para melhor desenvolver esses relacionamentos. Tem, pois, como objetivo principal analisar os relacionamentos entre produtores agropecuários e as cooperativas, propondo um plano de ação para melhorias desses relacionamentos.

Justifica-se esse estudo pelo crescente número de cooperativas do ramo agropecuário e, ao mesmo tempo, pela carência de estudos que tratam desses tipos de cooperativas, bem como a necessidade de buscar constantes melhorias que venham beneficiar as cooperativas e os associados.

\section{Referencial teórico}

O referencial teórico do presente estudo está divido em subitens, os quais fazem parte da literatura existente sobre cooperações e relacionamentos cooperativos.

Primeiramente trata-se conceitualmente da cooperação e cooperativa, após trata-se a cooperação sob a ótica social e humana para em seguida tratá-la sob a ótica econômica. 0 último subitem do capítulo traz à tona a discussão das razões para desenvolver relacionamentos cooperativos.

\section{Cooperação e cooperativa}

Encontra-se frequentemente na literatura que um pressuposto para a existência de cooperação é a existência anterior de capital social e Putnam (1993, p.1) define capital social como "características da organização social, tais como redes, normas e confiança, que facilitam a coordenação e a cooperação para benefício mútuo" e o mesmo autor afirma que trabalhar em conjunto é mais fácil em comunidades que possuem um substancial capital social, que 
propulsiona relações de confiança e cooperação. Nesse mesmo sentido, é necessário haver confiança prévia entre as partes que constituirão uma cooperação (GULATI, 1995). Compreende-se assim que a cooperação é desenvolvida a partir de laços que existem entre pessoas ou organizações, sendo que seu sucesso depende da forma como o capital social se constitui nesse relacionamento.

O capital social pressupõe uma consciência coletiva entre os cooperados, o que faz com que os indivíduos ajam de forma coletivista e não estritamente pelos interesses próprios (BITTENCOURT e ABRAMOVAY, 2003). Com essa abordagem e, visualizando-se empiricamente o número crescente dos mais diversos tipos de cooperações, compreende-se a cooperação como uma forma de os indivíduos buscarem alcançar seus objetivos individuais de forma coletiva. Nesse sentido, Müller-Seitz (2012) afirma que as cooperações têm sua importância por serem estratégias capazes de propiciar resultados que transcendem a soma dos recursos auferidos individualmente.

Tratando-se do enfoque desse estudo, qual seja estudar aspectos do relacionamento entre os produtores agropecuários e as cooperativas, as quais constituem-se uma forma de cooperação, torna-se importante conceituá-la. Segundo Vasconcelos (2011), uma cooperativa configura-se por ser uma sociedade de pessoas, sendo que o objetivo principal é a prestação de serviços aos associados. Essas possuem número ilimitado de cooperados e o controle democrático é baseado no voto paritário, sendo que cada cooperado representa um voto. Todas decisões são tomadas em assembleias, onde também decide-se o destino das sobras de recursos.

A sociedade cooperativa é uma organização de caráter permanente e, conforme Pedrozo (1993), criada por um agrupamento de indivíduos com interesses comuns, visando à realização de atividades econômicas relacionadas com o progresso econômico e o bem-estar dos associados, que são os proprietários e usuários da organização. Silva (1994, p.11) afirma ainda que as cooperativas se caracterizam por ser um "sistema econômico-social", que visa o bem-estar e a paz social dos produtores associados e não têm por objetivo somente o lucro (sobra). Jerônimo et al. (2005) complementa, afirmando que a finalidade principal de uma cooperativa tradicional é a melhoria da condição econômico-social de seus cooperados. Dadas essas características, tem-se que as cooperativas não possuem uma existência autônoma e independente de seus membros, do ponto de vista econômico, como ocorre nas sociedades de capital.

\section{A cooperação sob a ótica social e humana}

A cooperação, dentro das relações sociais, pode contribuir para a valorização das pessoas, e é importante para que aja o crescimento individual ou profissional (CASTRO; BULGACOV e HOFFMANN, 2011).

Mas, acima dos aspectos mais individualizados, as cooperações envolvem questões mais sociais e coletivas e, segundo Lima (2006) as parcerias caracterizam-se pela relevância que atribuem à complementaridade de esforços, pelos princípios de cooperação e solidariedade na realização de um programa social. Por meio da ideia de dádiva, constroem-se redes de reciprocidade e de solidariedade que envolvem estranhos e conhecidos. Diz respeito, portanto, ao conjunto das dimensões da ação que exerce profunda repercussão em toda a sociedade (TABOSA et al., 2007).

A dádiva pode ser entendida como a manifestação de toda ação social efetuada sem expectativa, garantia ou certeza de retorno e o paradigma da dádiva afirma a importância, positiva e normativa, sociológica, econômica, ética, política e filosófica desse tipo de ação social que os indivíduos venham demonstrar para a sociedade (CANÇADO; SILVA JÚNIOR e RIGO, 2008). 


\section{CONFIGURAÇÃO DOS RELACIONAMENTOS ENTRE PRODUTORES AGROPECUÁRIOS E COOPERATIVAS}

outro lado, a economia da dádiva de Mauss (1974) constitui a ideia de que as trocas têm um papel fundamental nas sociedades, uma vez que fundamenta as relações de solidariedade. A ideia de dádiva daí advinda repousa na compreensão de que a sociedade não se reduz à lógica do mercado ou do Estado, mas traduz uma pluralidade de lógicas não redutíveis entre si (TABOSA et al., 2007).

Existe, portanto, um caminho para se estabelecer a confiança como instrumento de cooperação individual e moldar novamente o elo social a partir do interesse pelo outro. Para Martins (2002, p.11), "se existe confiança, existirá a cooperação".

Nessa perspectiva, as cooperativas, pela natureza democrática na condução das atividades, pela primazia das pessoas e do trabalho sobre o capital, pela autonomia em relação ao estado, são identificadas como portadoras de um ideal societário voltado ao bem comum e, enquanto tal, ganham respaldo nas concepções sobre economia social e paradigma da dádiva (FAVACHO, 2012). A Figura 01 mostra a relação de dádiva entre as redes sociais que se estabelecem:
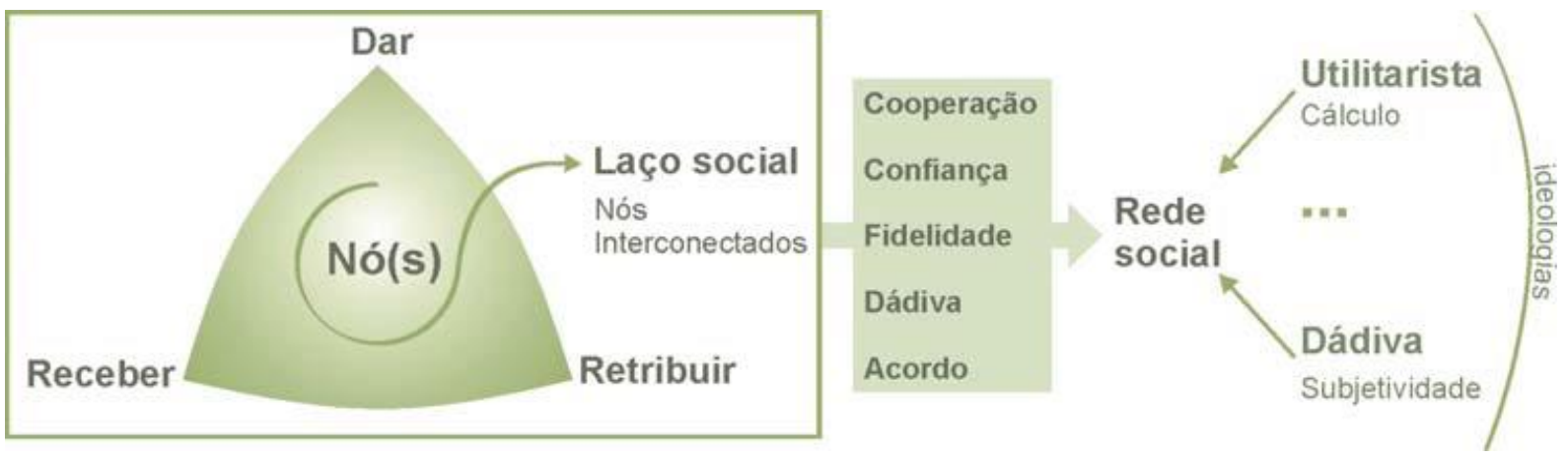

Figura 1: Relação Dádiva - Rede Social

Fonte: adaptada de Mauss (1974); Cordeiro e Mello (2006); Castells (1999) e Martinho (2002).

Com este conceito recíproco de dar, receber e retribuir forma-se um processo de solidariedade mútua, fortalecendo a confiança, pois no ato de dar existe mais que uma mera troca, existe todo um simbolismo que reforça valores humanos além dos valores econômicos envolvidos. Também nestes conceitos existe o elemento incerteza, isto é, quem recebe pode retribuir ou não. Neste caso se inverte o poder na relação, passando esse poder para aquele que recebeu a dádiva, o qual assume a posição de decidir se retribui ou não e quando (elemento tempo) irá retribuir (TESCHE, 2007).

Vale salientar que a reciprocidade é o sustentáculo da rede social - formada por laços sociais construídos, mantidos ou renovados em cada época, cultura e realidade social, política e econômica - que, aliada à intencionalidade instrumental, faz surgir e potencializar formas de cooperação sócio-econômicas específicas de organizações ou empreendimentos alternativos que vislumbram o desenvolvimento local sustentável (TABOSA et al., 2007).

Esse ciclo que se forma em uma cooperativa contribui para a participação ativa dos cooperados nas atividades e decisões, e então o associado passa a ser valorizado e bem visto na sociedade, sendo reconhecido como um cooperado de confiança (SILVA, 2006).

A ação cooperativa mostra-se mais efetiva onde existe a presença de instituições e relações sociais mantidas a partir da confiança e onde o comportamento oportunista seja minimizado mediante regulação social (COSTA e COSTA, 2005). Com este comportamento e confiança da 
população a cooperação refere-se à prática das pessoas ou entidades que trabalham juntas com acordos, metas e possivelmente métodos comuns ao invés de separadamente em competição (KHAMIS; KAMEL e SALICHS, 2007; LAGO, 2009).

A cooperação permite ser estudada sob a ótica social e humana, conforme exposto, mas também pode ser analisada sob a ótica econômica, conforme segue.

\section{A cooperação sob a ótica econômica}

Apresenta-se a seguir o Quadro 1, onde pode-se verificar que através da corrente teórica econômica, as redes interorganizacionais, por meio da cooperação, conseguem alcançar alguns importantes ganhos para as pequenas empresas, por exemplo, os derivados da especialização, os obtidos pelo compartilhamento de custos relativamente fixos diante de suas receitas reduzidas; e a assunção coletiva de atividades de pesquisa e desenvolvimento e, até mesmo a criação de bases coletivas para a exportação.

\begin{tabular}{|c|c|c|c|}
\hline \multirow[b]{2}{*}{$\begin{array}{l}\text { Abordagem } \\
\text { Econômica }\end{array}$} & $\begin{array}{l}\text { Formação, } \\
\text { Participação }\end{array}$ & $\begin{array}{l}\text { - As redes são resultado da busca } \\
\text { de minimização dos custos de } \\
\text { transação por parte dos agentes } \\
\text { econômicos. } \\
\text { - O lucro e o crescimento } \\
\text { sustentável são prováveis benefícios } \\
\text { do envolvimento em rede. Ainda, } \\
\text { salienta-se a obtenção de flexibilidade, } \\
\text { distribuição e custo-benefício, além da } \\
\text { capacidade de realizar economias } \\
\text { relacionais através da interconexão } \\
\text { entre os participantes. }\end{array}$ & \multirow{2}{*}{ 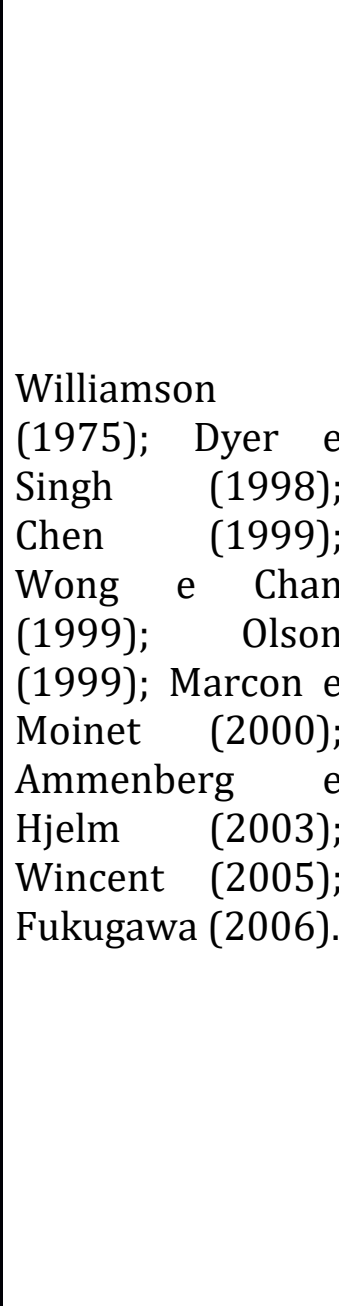 } \\
\hline & Desempenho & $\begin{array}{l}\text { - Os custos da cooperação são } \\
\text { mais reduzidos do que os benefícios } \\
\text { auferidos pelo ator. A deserção na ação } \\
\text { coletiva é racional, ou seja, sempre que } \\
\text { o efeito da contribuição de cada } \\
\text { indivíduo para a provisão do benefício } \\
\text { coletivo não exercer uma diferença } \\
\text { perceptível para o grupo como um } \\
\text { todo, ou para o ônus ou ganho de } \\
\text { qualquer membro do grupo tomado } \\
\text { individualmente. Sugere-se que o } \\
\text { tamanho da empresa é importante } \\
\text { para o comportamento e o } \\
\text { desempenho dentro da rede. }\end{array}$ & \\
\hline
\end{tabular}

Quadro 1 - Abordagem econômica sobre relacionamentos de cooperação.

Fonte: com base em Alves (2011) 


\section{CONFIGURAÇÃO DOS RELACIONAMENTOS ENTRE PRODUTORES AGROPECUÁRIOS E COOPERATIVAS}

Com base nestes conceitos de relações sociais e econômicas pode-se notar que os relacionamentos cooperativos estão presentes em ambos os sentidos, visando algum interesse de existir uma relação de confiança e um comportamento diferenciado perante o mercado atual, para com isso se pensar quais as formas melhores de cooperar e ter um resultado mais eficiente, minimizando riscos e perdas nas atividades desenvolvidas.

\section{Razões para desenvolver relacionamentos cooperativos}

Em se tratando dos motivos que levam ao desenvolvimento de cooperativas, pode-se destacar as vantagens auferidas por meio delas. Verschoore (2004) cita que o compartilhamento de recursos, ideias, experiências, conjunto de processos e inovação são melhorias intrínsecas desses relacionamentos e Stam (2010) afirma que relacionamentos de cooperações e as trocas de informações que ocorrem por meio desses são fontes para a identificação de novas oportunidades de negócios, aquisição de recursos financeiros e capital social.

Dadas as vantagens que podem ser auferidas ao se inserir em cooperativas, um quesito básico que deve existir para o sucesso das mesmas é a transparência nas transações e relacionamentos. Dalsgaard e Paulsen (2009) são incisivos ao afirmar que a transparência é a única característica das redes sociais que se formam. E disso depende a confiança que os cooperados depositarão na cooperativa para seu desenvolvimento. Putnam (1993) afirma que a confiança é necessária para que haja cooperação e que essa seja produtiva.

De qualquer forma, a cooperativa deve ser sustentável ao longo do tempo, desenvolvendo estratégias para tal. Barney (1991) afirma que os recursos devem ter quatro atributos para que possam ser considerados com potencial de geração de vantagem competitiva sustentável: ser valiosos (exploração de oportunidades ou neutralização de ameaças), raros, imperfeitamente imitáveis e não-substituíveis.

Desta forma abre-se espaço para discussão da Teoria da Visão Baseada em Recursos, que visa à construção de vantagens estratégicas, tendo em vista a heterogeneidade dos recursos disponíveis entre as firmas (MALAFAIA e BARCELLOS, 2006).

Estes recursos e suas vantagens estratégias trazem uma perspectiva que surgiu a partir dos trabalhos de Selznick (1957), Penrose (1959), e ampliada por Barney (1991) e Peteraf (1993), que sugerem que a vantagem competitiva está ligada ao fato de as empresas possuírem um conjunto de recursos mais apropriados às demandas colocadas pelos mercados onde elas atuam, obtendo assim vantagem competitiva. A esta perspectiva, chamou-se "Visão da Empresa Baseada em Recursos" (do inglês "Resource Based View of the Firm”, ou RBV).

0 argumento básico é que o RBV pode ser apropriado para a avaliação da importância estratégica dos relacionamentos de negócios e a visão em redes e em cooperativas pode aprimorar a compreensão da natureza e da relevância estratégica dos relacionamentos de negócios. O RBV pode espalhar uma luz em ambos os relacionamentos de negócios (quais características distinguem relacionamentos estratégicos dos não estratégicos), e as relevâncias estratégicas (quais consequências, em termos de capacidades, advêm do envolvimento da empresa em relacionamento de negócios estratégicos e não estratégicos) (ALVES, TIERGARTEN e ARAÚJO JR., 2008).

No próximo capítulo, apresentam-se os métodos, técnicas de coleta e análise das informações a 
serem obtidas junto aos pesquisados.

\section{Método de pesquisa}

Conforme Gil (1999), cada pesquisa social, naturalmente, tem objetivo específico. Para atingir o objetivo proposto, esse estudo possui cunho qualitativo-descritivo, onde qualitativo refere-se por traduzir e expressar o sentido dos fenômenos do mundo social e visa descrever uma amostra da população de produtores agropecuários associados a cooperativas..

A escolha da amostra do estudo deu-se por conveniência e representatividade em relacionamentos cooperativos, sendo composta por três produtores rurais que fazem parte de cooperativas dos municípios de Boa Vista do Cadeado - RS e de Pejuçara - RS, região tipicamente agrícola.

O estudo configura-se como um caso de produtores agropecuários vinculados a cooperativas, sendo operacionalizado com entrevistas semi-estruturadas. Desta maneira, foi elaborado um roteiro com as dimensões a serem estudadas e, à medida que a entrevista se desenvolvia, foram sendo questionados tópicos da prática de gestão relacionada à dimensão de estudo. As perguntas feitas durante a entrevista foram do tipo abertas, o que permite ao entrevistado responder às questões com as suas próprias palavras. As entrevistas foram realizadas pessoalmente pelos pesquisadores, sendo que primeiramente o entrevistador informou as diretrizes iniciais da busca de informação, tratando da importância do trabalho para identificar as práticas da gestão da empresa durante o período analisado. Cada entrevista foi previamente agendada, tendo a duração média de meia hora. As mesmas foram gravadas e, posteriormente, transcritas na íntegra para análise de conteúdo (BARDIN, 1977). Essa análise visou uniformizar os dados das entrevistas, bem como elaborar uma síntese das opiniões convergentes dos entrevistados, além de destacar as discordâncias e dissonâncias encontradas.

\section{Modelo Conceitual de Relacionamentos entre Produtor e Cooperativas.}

A partir do levantamento realizado no referencial teórico, apresenta-se na Figura 2, o modelo que norteia a coleta e análise de dados desse estudo.

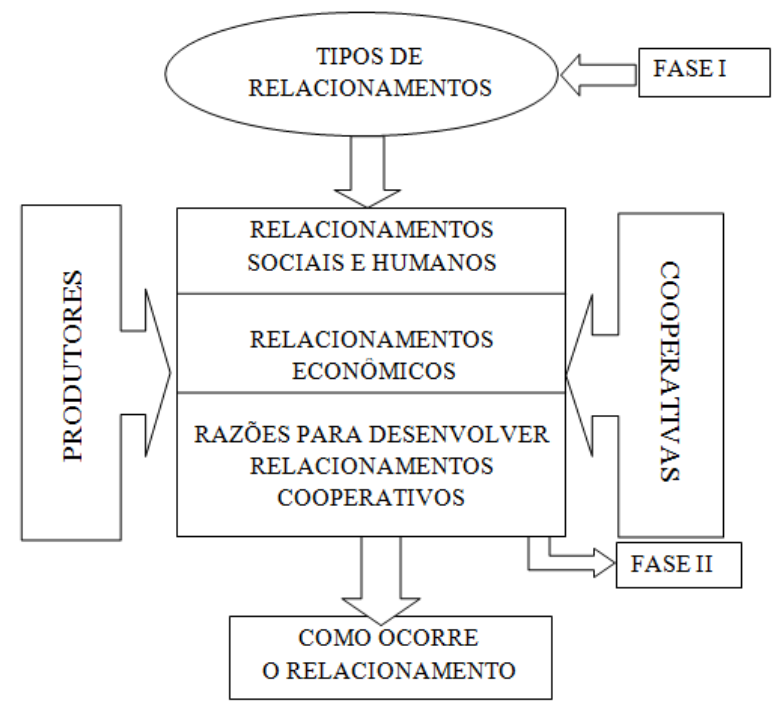

Figura 2: Modelo Conceitual de Relacionamento entre Produtor e Cooperativas. 


\section{CONFIGURAÇÃO DOS RELACIONAMENTOS ENTRE PRODUTORES AGROPECUÁRIOS E COOPERATIVAS}

Fonte: Elaborado pelos autores

Conforme fica estabelecido na Figura 4, a coleta de dados se estrutura em duas grandes fases, visando descrever primeiramente os tipos de relacionamentos que se estabeleceram com as cooperativas, salientando aspectos de relacionamentos humanos e sociais e também econômicos. E após, a fase II está relacionada à busca pela compreensão das razões que justificam o desenvolvimento dos relacionamentos entre produtores agropecuários e as cooperativas. A forma como será operacionalizada cada fase é descrita a seguir, no Quadro 2:

\begin{tabular}{|c|c|c|c|c|}
\hline FASE & FASE & $\begin{array}{ll}\text { COLETA } & \text { DE } \\
\text { DADOS } & \end{array}$ & $\begin{array}{l}\text { ANÁLISE } \\
\text { DADOS }\end{array}$ & $\begin{array}{l}\text { OBJETO } \\
\text { ANÁLISE }\end{array}$ \\
\hline FASE I & $\begin{array}{l}\text { Identificar os tipos de } \\
\text { relacionamentos } \\
\text { existentes entre produtor } \\
\text { e cooperativa. }\end{array}$ & $\begin{array}{l}\text { Entrevistas } \\
\text { semiestruturadas }\end{array}$ & $\begin{array}{l}\text { Análise de } \\
\text { Conteúdo }\end{array}$ & Produtores \\
\hline FASE II & $\begin{array}{l}\text { Identificar as razões para } \\
\text { que se desenvolvessem os } \\
\text { relacionamento. }\end{array}$ & $\begin{array}{l}\text { Entrevistas } \\
\text { semiestruturadas }\end{array}$ & $\begin{array}{l}\text { Análise de } \\
\text { Conteúdo. }\end{array}$ & Relacionamentos \\
\hline
\end{tabular}

Quadro 2 - Síntese das etapas da pesquisa e formas de coletas de dados.

Fonte: Elaborado pelos autores

\section{Análise dos resultados}

Após as entrevistas terem sido realizadas e transcritas, foi possível fazer o cruzamento dos dados, a fim de responder aos questionamentos que surgem a partir do modelo conceitual adotado, bem como ao objetivo desse estudo. Apresenta-se, a seguir, a discussão dos resultados encontrados.

\section{A ótica dos relacionamentos}

Sobre a ótica dos relacionamentos cooperativos, é possível classificá-los sob as óticas social e humana e econômica, e essas foram possíveis de ser identificadas nos resultados obtidos, conforme observa-se nos itens que seguem:

Importância das relações entre produtor agropecuário e cooperativas;

Sobre a importância das relações entre os produtores agropecuários e as cooperativas, destacase que a cooperação vem sendo abordada de diferentes maneiras e, no contexto das cooperativas, enfoque desse estudo, visualiza-se a tentativa de se associarem desempenhos empresarias com recursos complementares, conforme pode-se verificar nos relatos de alguns entrevistados:

(...) a minha cooperativa é agropecuária, atua em diferentes segmentos, tem grãos, insumos, mercado, prestação de serviços, veterinária (...).

(...) ela tem um corpo técnico disponível para seus associados usarem, os associados buscam opiniões, esclarecimentos, tiram suas dúvidas (...).

Observa-se nos relatos que os associados têm a assistência que precisam e que a cooperativa disponibiliza seus serviços gratuitamente, o que transpareceu ser crucial para o bom 
desenvolvimento do negócio do associado, onde se enxerga uma efetiva relação de cooperação entre ambos.

Com isso pode-se destacar também que as cooperativas se caracterizam por serem "sistemas econômico-sociais", que visam o bem-estar e a paz social dos produtores a ela associados e não têm por objetivo somente o lucro (sobra), conforme Silva (1994, p.11), sendo que a finalidade principal de uma cooperativa tradicional é a melhoria da condição econômico-social de seus cooperados (JERÔNIMO et al., 2005).

Para compreender melhor a importância das relações entre os produtores e as cooperativas, salientam-se os seguintes fragmentos:

E1: Preço melhor, ela tinha um preço que não tinha um desconto que nem uma empresa particular, ela te fazia quase um preço disponível, sem ter a taxa aquela que você deixa em uma empresa, isso não era para visar lucro. Essas coisas, por exemplo, de PRONAFIANO uma empresa particular não tem o bônus do BIODIESEL, e a cooperativa tem isso porque tem um certo subsidio do governo.

E2: Hoje ela oferece melhores negociações para nós e maior certeza nas operações que estamos fazendo com ela. Nós temos grande assistência técnica oferecida por eles, e uma grande satisfação nos produtos colocados ao produtor.

Pode-se ainda observar algumas razões que mostram os relacionamentos cooperativos mais na prática, através dos depoimentos abaixo destacados:

E2: 0 melhor beneficio é a transparência da cooperativa e a grande assistência que ela oferece aos produtores. E também por estar ligado à cooperativa negociando, obtendo melhores benefícios e lucratividade. [...] hoje a melhor forma de ligação à cooperativa é a assistência técnica prestada gratuitamente.

E3: Um dos benefícios é a busca de informação que eles trazem até você, e outro beneficio é a imparcialidade da cooperativa na hora de oferecer o produto para o produtor. Tipo assim, eles têm um corpo administrativo, que se reúne na área de planejamento da cooperativa, junto com técnico, financeiro e administrativo, e eles selecionam as empresas, no caso de multinacional, que oferece os produtos e estes produtos são oferecidos para o produtor sem serem socados, a força, o produtor tem a livre escolha de usar e definir as melhores opções, não é picaretagem que nem no mercado.

Nesses fragmentos, compreende-se a importância das cooperativas nos processos de tomada de decisão dos produtores, aspecto que concede diferencial ao relacionamento. Esse diferencial está associado aos mecanismos de aprendizagem possíveis em cooperativas. Segundo Lemos (2001), os mecanismos de aprendizagem, criados em cooperativas, são pressupostos para a inovação, que ocorre pela interação de variados agentes sócio-econômicos que possuem diferentes tipos de informações e conhecimentos. Nesse sentido, há uma troca de informações em cooperativas que conduz à aprendizagem, a qual dá apoio à tomada de decisões. 


\section{CONFIGURAÇÃO DOS RELACIONAMENTOS ENTRE PRODUTORES AGROPECUÁRIOS E COOPERATIVAS}

bastante ressaltado pelos entrevistados a importância das cooperativas nas negociações que realizam, coforme salientado abaixo:

E2: Melhor condição é das negociações que a gente tem com ela, por a gente estar ligado a eles, é a melhor forma que tem de ter um ganho financeiro. E de longo prazo, se torna muito mais fácil do que fazer em firmas particulares. Negociações anuais que se tem, consegue fazer compras muito mais fácil do que em firmas particulares, planos safras se tornam muito melhores (...) o nosso beneficio da cooperativa no final de cada ano, tem um retorno que vem para a conta corrente sobre as negociações feitas durante todo o ano, sobre as suas compras, vendas e a entrega dos produtos feitos anualmente.

Através dessas análises, pode-se observar a importância das cooperativas para os produtores agropecuários, as quais geram benefícios, por exemplo, sendo fonte de segurança nas negociações efetuadas. Também percebeu-se que algumas cooperativas estão mais ativas junto ao produtor, e essas estão mais preocupadas com as atividades de seus cooperados e buscam oferecer produtos e serviços para auxilia-los. Essa relação mais próxima entre produtor e cooperativa é tida como diferencial, os produtores valorizam-na e sentem mais confiança e segurança nas transações efetuadas.

A partir dessas colocações, cabe salientar a importância da melhoria contínua do relacionamento entre produtores e cooperativas, buscando assim atender às demandas e solicitações dos associados e contribuindo para a melhoria de suas condições de vida, observando a ótica social, humana e econômica.

A ótica social e humana

Sobre a ótica social e humana, pode-se destacar, conforme referencial teórico abordado, que há um caminho para se restabelecer a confiança, como instrumento de cooperação individual (MARTINS, 2002). De acordo com um dos entrevistados:

E3: (...) a cooperativa gerou no decorrer da sua vida, desde a sua criação até nos dias de hoje, uma certa credibilidade, só que assim, eu particularmente acho, até por ter feito parte do quadro de representantes da cooperativa, que ela conseguiria aumentar muito mais essa confiança se o modelo de administração fosse diferente. Como produtor, de repente você pensa uma coisa, agora como administrador da cooperativa nem sempre pode ser falado, levado à sabedoria do produtor, população, certos assuntos e informações. Mas acho que se certos critérios do que a cooperativa estabelece fossem mais expostos, mais trabalhados perante $o$ grupo de associados, o próprio associado se tornaria cada vez mais um divulgador da ideia de cooperativismo (...).

Observa-se que este associado quer que sua cooperativa divulgue mais as informações para o seu público, isso é essencial para fortalecer a confiança nos relacionamentos e aumentar a transparência das decisões e ações.

Dentro dessa perspectiva, as cooperativas, pela primazia das pessoas e do trabalho sobre o capital, pela autonomia em relação ao estado, são identificadas como portadoras de um ideal societário voltado ao bem comum e, enquanto tal, ganham respaldo nas concepções sobre 
economia social e paradigma da dádiva (FAVACHO, 2012).

Os conceitos referentes à Figura 01: Relação Dádiva - Rede Social puderam ser observados no seguinte fragmento de entrevista:

E3: Eles não lhe cobram reciprocidade, mas no momento de você necessitar, eles analisam a sua forma de trabalhar com a cooperativa, então vai muito da consciência do produtor de fazer a sua parte para depois ser beneficiado no que precisar, a cooperativa irá atender. Exemplo, se o produtor precisa de um crédito, pois hoje ela tem financiamentos para produtores diretos, ele solicita, passa pelas fases de aprovação, mas analisa a sua reciprocidade, quanto ele entrega para a cooperativa, proporcional a sua colheita, a cooperativa sabe quanto você colhe no total e olha sua entrega, analisando sua participação dentro dela... ou o devido produtor que está solicitando o crédito na hora de entregar levou para outro lugar, por um preço melhor, entre outros fatores, isso soma na analise. Um outro detalhe também que quando abre lotes de soja futuros, existe um percentual a fixar do produto, esse percentual é igual para todos os associados, não tem diferenciação entre associados.

Com este conceito recíproco de dar, receber e retribuir forma-se um processo de solidariedade mútua, fortalecendo a confiança, pois no ato de dar existe mais que uma mera troca, existe todo um simbolismo presente que reforça valores humanos além dos valores econômicos envolvidos.

Com essas informações, consegue-se observar que o relacionamento sob a ótica social e humana visa uma reciprocidade que acontece na prática, ou seja, os entrevistados sabem que isso é importante tanto para as cooperativas, quanto para si mesmos. No caso exposto, concessão de crédito, é analisada a reciprocidade do cooperado junto à cooperativa. Por outro lado, o produtor tem a ciência de que tem que haver a contra partida, mas não há uma exigência por parte das cooperativas.

Portanto, se isso for contínuo e ambos os lados estiverem atendendo seus objetivos, tendo uma relação de confiança, pode-se dizer que a cooperação está sendo fortalecida, o que cria novas oportunidades de negócios.

Dentro destes conceitos de relacionamentos sociais existe o elemento incerteza, isto é, quem recebe pode retribuir ou não. Neste caso se inverte o poder na relação, passando esse poder para aquele que recebeu a dádiva, o qual assume a posição de decidir se retribui ou não e quando (elemento tempo) irá retribuir (TESCHE, 2007).

Sendo assim, para compreender melhor a ideia de troca e reciprocidade, alguns entrevistados relatam que:

E1: (...) não cobram reciprocidade, não obrigam você a fazer, no caso, se você não tem dinheiro para girar, que não consegue comprar, aí você fica devendo em grão para a cooperativa, fazem isso para a safra, os pacotes.

E2: Eu procuro trabalhar mais com cooperativas, mas nenhuma delas pressiona a fazer a negociação com elas, é espontâneo, mas cada uma oferece melhor o seu produto, procura oferecer da melhor forma para obter este vínculo com o produtor, visando lucratividade para o produtor. 


\section{CONFIGURAÇÃO dOS RELACIONAMENTOS ENTRE PRODUTORES AGROPECUÁRIOS E COOPERATIVAS}

Questões de incerteza e segurança são relatadas nos fragmentos seguintes:

E1: Não tem mais como ter confiança, tu não vai entregar um produto se já foi prejudicado no passado, não existe mais confiança, não tem como voltar.

E2: Hoje não nos sentimos nada seguros em depositarmos e trabalharmos com as cooperativas que já foram prejudicadas, porque já tivemos dificuldades em negociações e ainda hoje se encontram em grandes dificuldades e não transmitem mais segurança ao produtor, até que elas não mostrem para os associados algo que possa melhorar, transparecer, e ter certeza para trabalharmos novamente com eles.

A explicação para os fatos ressaltados no relato a cima é de que algumas cooperativas passaram por dificuldades financeiras e não conseguiram reverter a situação perante o seu quadro social. Nesse contexto, vários associados foram prejudicados e a cooperativa não conseguiu reconquistar a confiança perante os mesmos e melhorar sua imagem. Nesse caso, o produtor fica com dúvida e insegurança nos seus negócios e, mesmo com a retomada da cooperativa, percebeu-se nas entrevistas que muitos associados não voltariam a confiar na mesma.

Faz-se, a seguir, referência quanto à ótica econômica dos relacionamentos cooperativos, que também é quesito importante em cooperações.

\section{A ótica econômica}

Conforme Silva (1994) e Lago (2009), a cooperação acontece de várias formas e todos cooperam entre si. Observa-se no trecho de uma entrevista a questão do aprendizado no contexto da cooperativa:

E3: A cooperativa tem muitos cursos, convênios com SENAE, SEBRAE, disponibiliza vários cursos, tanto na área rural, mulheres de sócios, juventude tem curso de computação, com custo zero. Isso chama atenção dos filhos que começam desde cedo o envolvimento com a cooperativa. Para os associados também, cursos de colheitadeiras, regulagem, plantio o que você imaginar é só formar grupos e solicitar que eles colocam na agenda de calendários para o ano. Para ter uma ideia nos tínhamos pensado em fazer um ano passado e não tinha agenda para o ano todo, só para 2013, isso também depende muito do associado, que o associado se relaciona bem com a cooperativa (...).

Com este relato, identifica-se que a cooperação vai além das atividades básicas, influenciando no aprimoramento dos conhecimentos dos associados, bem como de suas famílias. 0 avanço das formas de cooperação fazem os associados buscarem esses conhecimentos gratuitos e sentemse orgulhosos em receber seus certificados.

Dentro da ótica econômica, ressalta-se a questão do planejamento, o qual contribui no que tange o desafio dos proprietários de rentabilizar cada vez mais o seu negócio, o que é ressaltado nos fragmentos a seguir:

E2: Existe um planejamento nas cooperativas, e sem isso o produtor também não consegue atingir seu objetivo, se você não conseguir isso ao final de cada temporada ou final de cada ano, você não vai conseguir 
ampliar o seu negócio, e não vai se manter na atividade.

(...) mas a maioria das cooperativas das agropecuárias em si, atua em vários segmentos para atender a necessidade dos associados, varejo, frigorífico, insumos, grãos. 0 momento que um setor está em baixa o outro dá o suporte, e assim segue, por isso que depende de um planejamento bem estruturado para se ajudarem, sustentando, e muitos associados são contra sobre o varejo em si, principalmente quando estava como representante do conselho via que isso ajudava muito o pequeno produtor, que trabalha com o leite, tinha uma velha visão, ficar às vezes insatisfeito, porque trabalha o mês inteiro, e vai para fazer o acerto no final sobra pouco, porque ele gira dentro da cooperativa, já gastou na loja, compras, alimentos, ração, veterinária e às vezes fica devendo para o próximo mês, só que a cooperativa viabiliza o produtor nesse sentido, onde ela tendo um varejo grande, diversifica e também tem pessoas que não são sócios que adquirem produtos.

Nessa visão inovadora, consegue-se identificar que os produtores também trabalham a partir de um planejamento, de forma a seguir os pressupostos das cooperativas e mostrar resultados.

Já ressaltado por Filho, Lyra e Gomes (2007), pode-se também observar a influência da sociedade na cooperação, onde tem seus grupos de contato e fazem as informações chegarem a todos, nessa visão consegue-se verificar nos entrevistados suas preocupações com a sociedade, conforme os relatos:

E2: Na nossa região aqui praticamente todos trabalham com cooperativas, então isso valoriza a cooperativa e sua imagem perante a sociedade é boa, e todo mundo que trabalha junto, que se une e sabe procurar bons negócios, com certeza está aliado as cooperativas.

E3: Hoje se notam pessoas que criticam a cooperativa, mas vê muito mais pessoas que falam bem dela, tanto no município de abrangência dela, como na região no estado. É uma das cooperativas das primeiras no ranking estadual, pela sua solidez, com certeza está sendo sempre lembrada mais por elogios do que por críticas, até mesmo ultimamente a quantidade de sócios novos que tem aumentado, pessoas que eram terceiras, não sócios, que trabalhavam na entrega de grãos, optaram em se associar, pela forma de faturamento de grãos, e participar ativamente, totalmente de todas as suas atividades das cooperativas, sobras, lucros, porque oferece vários segmentos de serviços, isso faz com que ela seja bem vista em toda sua área.

Com estas ideias podemos afirmar que as imagens destas cooperativas perante a sociedade são positivas, isso fortalece a marca da organização, e mostra que é sempre lembrada pelas pessoas, podendo influenciar nos seus pensamentos para mostrar que com a cooperação é mais fácil de atingir os objetivos, até porque o cooperativismo esta cada vez mais forte e vive-se um momento de cooperar, porque isso é moderno e traz excelente resultados.

\section{Principais razões para o desenvolvimento de relacionamentos entre produtores e cooperativas}




\section{CONFIGURAÇÃO DOS RELACIONAMENTOS ENTRE PRODUTORES AGROPECUÁRIOS E COOPERATIVAS}

relação aos relacionamentos dos produtores com as cooperativas pode-se verificar que os produtores tornam-se cooperados por diferentes razões, desde que essas favoreçam o seu ganho nas negociações feitas, para poder gerar mais renda a suas famílias e propriedades.

Sendo assim, para entender como acontecem os relacionamentos dos produtores e cooperativas, apresentam-se os seguintes relatos:

E2: Porque é a melhor forma de trabalhar hoje, por ser pequenos produtores e não temos condições de armazenar nossos produtos na propriedade, aí a melhor forma de fazer estas negociações, com certeza, é com as cooperativas.

E1: A cooperativa consegue barganhar preço até em compra de insumos para o produtor, o governo dá uma mão, tem alguma ajuda do governo, consegue te dar mais prazos que uma empresa particular, não cobra o juro que uma empresa particular cobra.

E3: Atualmente eu me relaciono com 1 cooperativas de produção, relação normal de cooperativa e produtor [...] a minha relação com eles se dá basicamente na entrega de grãos e na busca de assistência técnica e insumos para o planejamento da lavoura, eles dispõem de uma certa gama de informação e todo associado tem à disposição, basta ir a procura das informações.

Retoma-se aqui aspectos ressaltados no referencial teórico, quando os entrevistados trataram das razões para que se desenvolvessem os relacionamentos.

E3: Eles fazem explanação técnica com um grupo maior de associados, onde eles levam a informação, isso através de reuniões com datas agendadas, com pesquisadores junto. A partir disso que eles explanam para um grupo maior, desperta o interesse do associado, aí o associado tem um corpo técnico que tem acesso a qualquer hora do dia, conversa, busca informações atualizadas, solicita para vim até a sua propriedade para melhores esclarecimentos e também tem acesso à parte administrativa, que a cooperativa ajuda, presta informações sobre planejamento e administrativa da lavoura, aplicações de recursos, épocas, aquisições de insumos, planejamento financeiro da lavoura, sempre visando que o produtor obtenha mais resultado final, lucro.

E2: Toda a assistência possível, tanto ao produtor para obter mais produtividade, quanto na negociação de seu produto, gratuita.

Em relação a essas formas de relacionamentos que a cooperativa disponibiliza para seus associados, o atendimento de suas demandas e os benefícios para suas atividades, os associados sentem-se orgulhosos por receber o atendimento diferenciado. Isso mostra que a cooperativa tem um foco constante em seus associados, além dos serviços prestados, contribui para que o produtor tenha um ganho financeiro dentro de sua atividade.

A percepção de cada vez mais o associado obter um ganho financeiro, de ter algo como vantagem para seu negócio foi possível de ser observada nos fragmentos seguintes: 
E1: (...) é o associado comprar mais barato os produtos e, como se diz, a cooperativa não tem aquele juro que tem uma empresa particular, que cobra $1,5 \%$ até, às vezes, $1,6 \%$ a.m. A cooperativa não cobra isso, e se você se aperta para pagar ela não te cobra juros e dá prazo ou faz troca com produtos.

E3: No financeiro em si, o produtor fazendo uma planta mais econômica para o seu lado, tu vai chegar no teu foco final com menor custo e, tendo menos custos, consegue se planejar para aumentar os resultados financeiros, isso comprando e negociando com a cooperativa é viável.

(...) para cada saco de produto vendido, soja, o produtor teve $\mathrm{R} \$ 0,06$ por saco de retorno, enquanto for ver tipo loja, mercado, o varejo em si dá mais o retorno para o associado, isso força ao associado em adquirir os insumos dentro da cooperativa, não só como associado, entregar o grão, mas mais ainda, movimentar dentro da cooperativa no que ele precisar, atender na plenitude de seus negócios.

Essas razões são importantes, pois além de a cooperativa fazer seu lado social, prestar todas as devidas assistências disponíveis, mostra e concretiza que o associado tem o ganho financeiro. É beneficiado com essas vantagens de agregar mais valor no seu produto final, visando o aumento dos seus resultados financeiros dentro de suas atividades. Isso comprova as razões de os relacionamentos cooperativos desenvolverem-se e evoluírem.

Ainda foi possível perceber algumas vantagens auferidas pelos entrevistados quando fazem parte de cooperativas, essenciais no desenvolvimento desses relacionamentos:

E2: (...) uma vantagem também é o retorno em dinheiro para sua conta corrente, onde pode utilizar em produtos nas lojas ou através de serviços deles. Através de um critério que é sobre a sua produção e sobre sua movimentação, compras durante todo o ano feitas nessa cooperativa, retorna para os seus associados (...) as outras 2 não trabalham dessa forma com os associados.

E3: Isso retorna em forma de cota capital para o associado, agora mudou o estatuto, antes ficava retino em uma conta, hoje é disponibilizado para o associado, entra na sua conta, aí se ele quiser pagar gastos que já comprou, ou retirar em compras, produtos, ele pode.

Observa-se que as construções de vantagens competitivas existem dentro das cooperativas, onde se cria alguma estratégia para devolver o lucro das cooperativas aos seus associados, pois isso é a essência das cooperativas. Mas nem todas conseguem fazer isso, às vezes pelo fato de estarem passando por alguma dificuldade financeira e não apresentarem um resultado positivo. Mas sabe-se que o associado valoriza esses critérios utilizados de distribuição de lucros, pois isso dá sustentação ao seu negócio, bem como à cooperativa, a qual trasnmite confiabilidade e segurança.

Portanto, a partir dos relatos, pode-se verificar que os relacionamentos entre produtores e as cooperativas analisadas acontecem principalmente devido aos ganhos que os mesmos conseguem nas cooperativas, o que havia sido salientado no referencial teórico levantado 


\section{CONFIGURAÇÃO dOS RELACIONAMENTOS ENTRE PRODUTORES AGROPECUÁRIOS E COOPERATIVAS}

(STAM, 2010).

Entendendo como estão configurados os relacionamentos entre produtores e cooperativas pode-se buscar entender os motivos que levam à manutenção desses relacionamentos, tanto a nível social quanto a nível econômico.

\section{Proposta de melhoria do relacionamento entre Produtor e Cooperativa}

A partir dos relatos dos entrevistados e a análise dos dados, pode-se sugerir uma proposta de melhoria nos relacionamentos, a qual se encontra no Quadro 3, de acordo com os tópicos abordados no referencial teórico.

\begin{tabular}{|c|c|c|}
\hline \multicolumn{3}{|c|}{ ÓTICA DOS RELACIONAMENTOS } \\
\hline Sugestão & Forma de Ação & Expectativa de Resultado \\
\hline $\begin{array}{llr}\text { Melhorar } & \text { a } \\
\text { transparência para os } \\
\text { associados. }\end{array}$ & $\begin{array}{l}\text { Realização de reuniões; } \\
\text { Contato telefônico e atendimento presencial } \\
\text { mais esclarecedor; } \\
\text { Esclarecimento constante de dúvidas e } \\
\text { questões pendentes dos produtores. }\end{array}$ & $\begin{array}{l}\text { Aumento das negociações, vendas; } \\
\text { Aumento da confiança; } \\
\text { Mais segurança para os associados } \\
\text { fazerem suas transações em conjunto } \\
\text { com a cooperativa. }\end{array}$ \\
\hline \multicolumn{3}{|c|}{ ÓTICA SOCIAL E HUMANA } \\
\hline Sugestão & Forma de Ação & Expectativa de Resultado \\
\hline $\begin{array}{lr}\text { Repassar } & \text { mais } \\
\text { informações } & \text { e } \\
\text { aperfeiçoar } & \text { os } \\
\text { conhecimentos } & \text { técnicos } \\
\text { dos produtores. } & \end{array}$ & $\begin{array}{l}\text { Reuniões técnicas; } \\
\text { Fazer treinamentos e repassar técnicas para } \\
\text { obter uma melhor planta ou colheita, ajudar } \\
\text { a fazer a gestão da propriedade; } \\
\text { Usar mais a mídia disponível e criar } \\
\text { programas de rádio para informes de } \\
\text { indicadores. }\end{array}$ & $\begin{array}{l}\text { Melhora o conhecimento do produtor } \\
\text { no que tange sua atividade } \\
\text { econômica; } \\
\text { Gera um melhor ganho financeiro e } \\
\text { aproveitamento de tempo, o que } \\
\text { reflete em ganhos para cooperativa; } \\
\text { Aumento de confiança e credibilidade } \\
\text { do produtor na cooperativa; } \\
\text { Manter o produtor atualizado no } \\
\text { mercado. }\end{array}$ \\
\hline \multicolumn{3}{|l|}{ ÓTICA ECONÔMICA } \\
\hline Sugestão & Forma de Ação & Expectativa de Resultado \\
\hline $\begin{array}{l}\text { A cooperativa deve } \\
\text { manter uma imagem } \\
\text { sempre ativa na } \\
\text { comunidade. }\end{array}$ & $\begin{array}{l}\text { Ter uma participação mais ativa nas } \\
\text { comunidades do interior, fazendo-se } \\
\text { presente em eventos locais; } \\
\text { Atuar em causas sociais na comunidade, } \\
\text { levando cursos, treinamentos, contribuindo } \\
\text { com entidades carentes. } \\
\text { Mostrar resultados práticos para os } \\
\text { associados. }\end{array}$ & $\begin{array}{l}\text { Melhorar e fortalecer a imagem da } \\
\text { cooperativa perante a comunidade; } \\
\text { Tornar a cooperativa e o } \\
\text { cooperativismo conhecidos na } \\
\text { comunidade; } \\
\text { Proporcionar um sentimento de } \\
\text { orgulho no associado por fazer parte } \\
\text { da cooperativa; } \\
\text { Ser referência na comunidade local, e } \\
\text { ser solicitada; }\end{array}$ \\
\hline \multicolumn{3}{|c|}{ RAZÕES PARA DESENVOVER RELACIONAMENTOS } \\
\hline Sugestão & Forma de Ação & Expectativa de Resultado \\
\hline $\begin{array}{lr}\text { Fortalecer seus critérios } \\
\text { de distribuição } \\
\text { sobras, }\end{array}$ & $\begin{array}{l}\text { Em cada negociação, mostrar o quanto o } \\
\text { produtor irá ter de retorno, tornar isso } \\
\text { tangível; } \\
\text { Criar uma rotina interna para que todos os } \\
\text { colaboradores possam sanar dúvidas dos } \\
\text { produtores. }\end{array}$ & $\begin{array}{l}\text { Fidelização do cooperado em uma } \\
\text { única cooperativa. }\end{array}$ \\
\hline $\begin{array}{l}\text { Aperfeiçoar } \\
\text { atendimento } \\
\text { diferenciais. }\end{array}$ & $\begin{array}{l}\text { A cada atendimento, frisar que o produtor é } \\
\text { especial para a cooperativa; } \\
\text { Valorizar e torná-lo mais próximo dos seus } \\
\text { negócios; } \\
\text { Durante a negociação, criar rotinas que } \\
\text { possibilitem aos proprietários perceberem } \\
\text { que estão recebendo condições especiais e } \\
\text { diferenciadas. }\end{array}$ & $\begin{array}{l}\text { Melhora a confiança; } \\
\text { Otimização de resultados para } \\
\text { produtor e cooperativa; } \\
\text { Formação de um relacionamento } \\
\text { mais amigável, mais próximo, entre } \\
\text { produtor e cooperativa. }\end{array}$ \\
\hline
\end{tabular}


Quadro 3 - Propostas de melhorias

Fonte: Elaborado pelos autores

\section{Considerações finais}

0 presente estudo buscou verificar como se configuram os relacionamentos entre produtores agropecuários e cooperativas, esse objetivo realizou-se por duas óticas importantes no âmbito dos relacionamentos cooperativas que é as ótica social e humana e por outro a ótica econômica principalmente para sustentar proposições de melhorias nesses relacionamentos.

A realizado do estudo foi realizado por entrevistas semi-estruturadas com produtores de uma região tipicamente agrícola e a escolha dos produtores foi por conveniência e vivência em relacionamentos cooperativos.

O que proporcionou resultados significativos tanto para os relacionamentos analisados quanto para demais relacionamentos entre produtor e cooperativa, mesmo que tenha limitaçõe por se tratar de um estudo de caso.

Sobre as óticas analisadas no que tange as análises da ótica social e humana, pode-se observar que a relação de reciprocidade é importante para os relacionamentos, sendo que a cooperativa será cada vez mais forte se o associado tiver negociações mais frequentes com ela. E, nessa lógica, o produtor tem ciência de que o seu retorno é proporcional à movimentação que realização na cooperativa.

Uma questão a ser trabalhada refere-se à incerteza por parte de alguns associados, sendo que esse sentimento foi observado quando os mesmos referiam-se a transações dele ou outros associados com a cooperativa. Para buscar recuperar esse sentimento é necessário um trabalho de longo prazo a ser realizado pelas cooperativas no sentido de aproximar-se dos cooperados e, de forma transparente, refazer os laços de confiança.

O segundo grupo de categorias relaciona-se à cooperação sob a ótica econômica. Dessa categoria pode-se salientar que os benefícios possíveis de serem auferidos pelos cooperados, além de aspectos inovadores, imagem da cooperativa e efetiva participação e integração, contribuem para a percepção sob a ótica econômica do produtor. Esses fatores identificam, sob a ótica econômica, aquilo que o produtor acessa, podendo influenciar na tomada de decisões quando da escolha do que é mais viável para sua atividade. Pressupõe, também que a cooperação é uma estratégia que facilita o alcance dos objetivos individuais dos produtores.

A partir dessas duas óticas no presente estudo foi possível verificar o objetivo principal do presente artigo através das das principais razões para o desenvolvimento dos relacionamentos entre os produtores agropecuários e as cooperativas, salientam-se as vantagens que se auferem em cooperações, destacando-se as vantagens competitivas para o associado, bem como retorno financeiro e de conhecimento. Apesar do reconhecimento dessas vantagens, percebeu-se um vínculo natural de cooperação, sendo que uns relacionam-se mais e outros menos, dados laços anteriores existentes.

Sendo assim, o que fica mais evidente quanto ao desenvolvimento desses relacionamentos é que no início da relação o produtor busca um beneficio para o seu negócio, alguma vantagem para sua atividade econômica, podendo ser uma redução de custos, melhor qualidade de serviços de 


\section{CONFIGURAÇÃO DOS RELACIONAMENTOS ENTRE PRODUTORES AGROPECUÁRIOS E COOPERATIVAS}

financiamento, acesso a informações do setor. Ainda, a cooperativa que conseguir vender essa vantagem da melhor forma irá conseguir conquistar mais um associado, devendo então aprimorar questões que visem à fidelização.

Por fim, buscando avanços nos estudos sobre relacionamentos entre produtor e cooperativas pode-se considerar que deve-se dar uma atenção maior a novos estudos sobre conhecimento e principalmente no compartilhamento de informações entre cooperativa e cooperados e assim resultando em melhores relacionamentos entre os envolvidos.

Destacam-se também algumas limitações relacionadas à pesquisa, tais como o acesso a poucos cooperados e a amostra restrita aos produtores agropecuários. E dadas essas limitações, sugerese ampliar a amostra desse estudo, podendo-se fazer um estudo quantitativo. Ainda, também poderiam ser abordados os gestores das cooperativas. Além disso, seria interessante um paralelo entre a realidade da relação com cooperativas dessa região do Rio Grande do Sul com outras diferentes regiões do Brasil ou do mundo.

\section{Referências}

ALVES, C. A.; TIERGARTEN, M.; ARAÚJO JR., J. P. Vantagem Competitiva a partir de uma Abordagem de Redes: Estudo de Caso da Rede Graphia. Revista de Administração da UNIMEPRAU, v. 6, n.3, 2008.

ALVES, J. N. Gestão de Redes: a arte da geração de novos benefícios. Dissertação (Mestrado em Administração) - Universidade Federal de Santa Maria. Santa Maria 2011.

BARDIN L. Análise de conteúdo. Lisboa: Edições 70; 1977.

BARNEY, J. Firm resousers and sustained competitive advantage. Journal of Management, v. 17, p: 99-120, 1991.

BITTENCOURT, G.; ABRAMOVAY, R. Inovações institucionais no financiamento à agricultura familiar. Revista Economia Ensaios, v. 16, n. 1, 2001.

CANÇADO, A.; SILVA JÚNIOR, J. T.; RIGO, A. S. Identidade, valores e governança das cooperativas. In. V Encontro Latino Americano de Pesquisadores da ACI, 2008. Anais... FEARP/USP, Ribeirão Preto/SP, 2008.

CASTELLS, M. A sociedade em rede: a era da informação: economia, sociedade e cultura. Vol. I. 2.ed. São Paulo: Paz e terra S.A., 1999.

CASTRO, M. de; BULGACOV, S.; HOFFMANN, V. E. Relacionamentos interorganizacionais e resultados: estudo em uma rede de cooperação horizontal da região central do Paraná. Revista de Administração Contemporânea, v.15, n.1, p.25-46, 2011.

CONSTANTINO, 0. J. A dinâmica de funcionamento das cooperativas de produtores de leite da agricultura familiar com interação solidária dos municípios de Ampére, Dois Vizinhos e Itapejara do Oeste. INFOCOS-Instituto de Formação do CRESOL Baser, p. 376, 2010.

CORDEIRO, A. T.; MELLO, S. C. B. de. Rupturas, permanências e ressignificações na estrutura 
discursiva do empreendedorismo. In: XXX Encontro da ANPAD, 2006. Anais... Salvador, 2006.

COSTA, B. A.; COSTA, M. B. Cooperação e capitais sociais em arranjos produtivos locais. Área ANPEC: ÁREA 8 - Economia Industrial e da Tecnologia, 2005.

COUTINHO, L. G.; FERRAZ, J. C. Estudos da competitividade da indústria brasileira - Sistema de indicadores da competitividade. Campinas: UNICAMP/UFRJ/PDC/FUNCEX, 1993.

DALSGAARD, D.; PAULSEN, M. F. Transparency in Cooperative Online Education. The International Review of Research in Open and Distance Learning, v. 10, n. 3, 2009.

FAVACHO, A. S. S. Gestão de cooperativas. Dissertação (Mestrado em Administração) Universidade da Amazônia, 2012.

FILHO, H. Z.; LYRA, M. M.; GOMES, V. C. A. Cooperação nas redes interorganizacionais do APL de Rochas ornamentais de Cachoeiro de Itapemirim - ES. In: Encontro Nacional de Engenharia de Produção, 2007. Anais... ENEGEP, 2007.

GIL, A. C. Métodos e técnicas de pesquisa social. 5.ed. São Paulo: Atlas, 1999.

GULATI, R. Social structure and alliance formation patterns: a longitudinal analysis. Administrative Science Quarterly, Ann Harbor, v. 40, p. 619-652. 1995.

JERÔNIMO, F. B.; PEDROZO, E. A.; FENSTERSEIFER, J. E.; SILVA, T. N. Redes de cooperação e mecanismos de coordenação: a experiência da rede formada por sete sociedades cooperativas no Rio Grande do Sul. Sociedade Brasileira de Economia e Sociologia Rural. SOBER, Ribeirão Preto, 24, 2005.

KHAMIS, A. M.; KAMEL, M. S.; SALICHS, M. A. Cooperation: concepts and general typology. In: Conference Proceedings - IEEE International Conference on Systems, Man and Cybernetics, 2006. Anais... Madrid, 2007.

LAGO, A. Fatores condicionantes do desenvolvimento de relacionamentos intercooperativos no Cooperativismo Agropecuário. Tese (Doutorado em Agronegócios) Universidade Federal do Rio Grande do Sul. Porto Alegre: UFGRS, 2009.

LEMOS, C. Inovação em Arranjos e Sistemas de MPME. Nota Técnica 1.3. Rede de Sistemas Produtivos e Inovativos Locais - RedeSist, Universidade Federal do Rio de Janeiro, Rio de Janeiro. 2001.

LIMA, L. M. Cooperação, o que vem a ser?. Revista Hegemonia, v.1, n.2, p.1-18, 2006.

MALAFAIA, G. C.; BARCELLOS, J. O. J. Sistemas agroalimentares locais e a Visão Baseada em Recursos: construindo vantagens competitivas para a carne bovina gaúcha. Revista de Economia e Agronegócio, v. 5, n. 1, p. 25-49, 2006.

MARTINHO, C. Algumas palavras sobre rede. Publicado Rede DLIS; 2002.

MARTINS, P. H. A dádiva entre os modernos: discussão sobre os fundamentos e as regras do social. Petrópolis: Vozes, 2002. 


\section{CONFIGURAÇÃO DOS RELACIONAMENTOS ENTRE PRODUTORES AGROPECUÁRIOS E COOPERATIVAS}

MAUSS, M. Ensaio sobre a dádiva: forma e razão da troca nas sociedades arcaicas. São Paulo: EPU; Edusp, 1974.

MÜLLER-SEITZ, G. Leadership in interorganizational networks: a literature review and suggestions for future research. International Journal of Management Reviews, v. 14, n. 4, p. 428-433, 2012.

OLIVEIRA, D. P. R. Planejamento Estratégico: conceitos, metodologias e práticas. 21. ed. São Paulo: Atlas, 2004.

PEDROZO, E. A. Análise de cooperativas agrícolas através da utilização de estratégias industriais. In: Encontro Nacional da ANPAD, 1993. Anais... Salvador/BA, 1993.

PENROSE, E. T. Facteurs, conditions et mécanismes de la croissance de l'entreprise. Neuilly-sur-Seine: Editions Hommes et Techniques, 1959.

PETERAF, M. A. The cornerstones of competitive advantage: a resource-based view. Strategic Management Journal, v. 14, n. 3, p. 179-191, Mar. 1993.

PUTNAM, R. D. The prosperous community: social capital and public life. The American Prospect, n. 13, Spring, 1993.

SELZNICK, P. Leadership and administration. New York : Harper \& Row, 1957.

SILVA, T. N. A participação de cooperados na gestão de cooperativas de produção: uma análise da separação entre propriedade e controle. Perspectiva Econômica, São Leopoldo, v.29, n.86, jul./set. 1994.

SILVA, C. L. Proposta de um modelo de monitoramento e avaliação do desenvolvimento sustentável. In: SILVA, C. L. (Org.). Desenvolvimento sustentável: um modelo analítico integrado e adaptativo. Petrópolis: Vozes, 2006. p.15-28.

STAM, W. Industry Event Participation and Network Brokeage among Entrepreneurial Ventures. Journal of Management Studies, v. 47, n. 4, 2010.

TABOSA, T. C. M.; TSCHÁ, E. R.; CABRAL, G. G.; PAIVA, F. G. Redes sociais, dádiva e cooperação na intervenção social transformadora: o caso do Projeto Imaginário Pernambuco - Brasil. 2007.

TESCHE, R. W. As relações de reciprocidade e redes de cooperação no desempenho socioeconômico da agricultura familiar: o caso dos produtores de leite do município de Sete de Setembro/RS. 2007.

VASCONCELOS, A. M. Formação dos catadores de materiais recicláveis cooperação. Projeto de Apoio a Projetos de Catadores de Materiais Recicláveis. São Paulo, outubro de 2011.

VERSCHOORE, J. R. Redes de cooperação: uma nova organização de pequenas e médias empresas no Rio Grande do Sul. Porto Alegre: FEE, 2004. 